\title{
Pengembangan Aplikasi Android Belajar Kriptografi Sebagai Media Pembelajaran Mata Kuliah Kriptografi
}

\author{
Hendy ${ }^{1}$, Habibullah Akbar ${ }^{2}$ \\ 1,2 Teknik Informatika, Universitas Esa Unggul \\ J. Arjuna Utara No.9, 11510, Jakarta Barat, Indonesia
}

email: ${ }^{1}$ hendyalgorithm@programmer.net, ${ }^{2}$ habibullah.akbar@esaunggul.ac.id

\begin{abstract}
Informasi Artikel Diterima: 23-11-2020 Direvisi: 24-12-2020

Disetujui: $15-02-2021$

\section{Abstrak}

Kriptografi merupakan salah satu mata kuliah yang biasanya terdapat didalam program studi teknik informatika maupun sistem informasi. Mata kuliah ini dirasakan cukup sulit khususnya bagi mahasiswa yang baru mendengar istilah ini. Banyak mahasiswa yang merasa kegiatan perkuliahan belum mencukupi sehingga mereka mencari tutorial kriptografi ataupun contoh-contohnya didalam internet menggunakan gawai. Untuk mengatasi kesulitan ini, kami melakukan pengembangan sebuah aplikasi berbasis android yang berfungsi sebagai media pembelajaran untuk menjelaskan kepada para mahasiswa cara-cara untuk menuntaskan topik-topik didalam mata kuliah kriptografi. Aplikasi ini dikembangkan menggunakan metode Rapid Application Development. Aplikasi ini memiliki nilai SUS (System Usability Scale) rata-rata sebesar 73,255\% dan tingkat persetujuan ahli materi diatas $80 \%$ dan pengguna diatas $70 \%$ berdasarkan survei yang telah dilakukan. Dengan demikian, aplikasi "Belajar Kriptografi" ini diharapkan dapat membantu para mahasiswa agar dapat lebih memahami materi di dalam mata kuliah kriptografi
\end{abstract}

Kata Kunci: kriptografi, android, media pembelajaran

\begin{abstract}
Cryptography is one of the courses within informatics engineering or information system programs. This course is quite difficult, especially for students who are just hearing this term. Many students feel that lecture activities are not sufficient so they look for cryptography tutorials or examples on the internet using smartphones. To overcome this difficulty, we developed an android-based application that functions as a learning medium to explain to students how to complete topics in cryptography courses. This application was developed using the Rapid Application Development method. This application has an average SUS (System Usability Scale) value of 73,255\% and a level of approval from material experts above $80 \%$ and users above $70 \%$ based on a survey that has been conducted. Thus, the application "Learning Cryptography" is expected to help students to better understand the material in the cryptography course.
\end{abstract}

Keywords: cryptography, android, learning media

\section{Pendahuluan}

Kriptografi adalah sebuah ilmu atau seni yang berguna sebagai penjaga kerahasiaan pesan dengan cara mengubah pesan ke dalam bentuk yang tidak dapat dimengerti lagi maknananya (Simargolang, 2017). Kriptografi juga bisa diartikan sebagai sebuah ilmu untuk menyamarkan / merubah bentuk pesan yang asli menjadi sebuah pesan yang tidak bisa diketahui atau dimengerti (Limbong, 2015). Kriptografi merupakan sebuah salah satu mata kuliah yang dipelajari oleh para mahasiswa di universitas. Materi-materi di dalam mata kuliah kriptografi dapat dikatakan banyak karena biasanya di dalam sebuah pertemuan kuliah akan membahas mengenai tata cara melakukan suatu metode kriptografi. Metode kriptografi ada banyak dan beragam karena ada banyak algoritma yang terkait dengan metode kritografi. Contoh-contohnya adalah operasi XOR, Vigenere Cipher, Caesar Cipher, RSA, dan masih banyak lagi. Banyaknya metode-metode kriptografi yang beragam membuat mahasiswa kesulitan memahami materi-materi di dalam mata kuliah kriptografi. 
Tugas-tugas yang diberikan oleh dosen pengampu sehubungan dengan mata kuliah kriptografi pasti menyangkut metode-metode kriptografi yang telah dijelaskan kepada mahasiswa. Tugas-tugas ini biasanya berbentuk pertanyaan yang meminta penjelasan tentang bagaimana sebuah hasil dari metode kriptografi tertentu dapat diperoleh. Permasalahan yang terdapat di dalam tugastugas ini pasti bersifat konstan karena di dalam sebuah metode kriptografi terdapat algoritma yang serupa. Permasalahan ini sulit ditemukan solusinya karena tidak ada sebuah perangkat lunak yang mampu memberikan penjelasan sehubungan dengan melakukan metodemetode kriptografi tertentu (contoh aplikasi: "Crypto - Tools for Encryption \& Cryptography", "Belajar Kriptografi RC4 \& RSA").

Perangkat lunak merupakan serangkaian instruksi yang dipahami oleh perangkat keras pengolahan data atau komputer, sehingga perangkat keras itu dapat melaksanakan pemrosesan data sesuai dengan yang dikehendaki (Irawan, 2017). Perangkat lunak perlu dikembangkan agar dapat menyelesaikan permasalahan yang telah dipaparkan. Android yang adalah sebuah sistem operasi pada smartphone yang bersifat terbuka dan berbasis pada sistem operasi Linux (Suryadi et al., 2018) dan dipilih untuk menjadi sebuah basis sistem operasi implementasi perangkat lunak "Belajar Kriptografi".

Jenis perangkat lunak yang dikembangkan adalah media pembelajaran. Media Pembelajaran adalah segala sesuatu seperti alat, lingkungan dan segala bentuk kegiatan yang dikondisikan untuk menambah pengetahuan, mengubah sikap atau menanamkan keterampilan pada setiap orang yang memanfaatkannya (Akbari et al., 2015). Media pembelajaran yang terdapat pada perangkat lunak ini akan memaparkan langkah penyelesaian sebuah soal kriptografi yang dimasukan ke dalam perangkat lunak.

\section{Metode Penelitian}

Metode penelitian yang digunakan adalah campuran yaitu kualitatif dan kuantitatif. Diagram tahapan metode penelitian digambarkan secara garis besar pada Gambar. 1. Pertama kami menggunakan pendekatan kualitatif yaitu observasi dan wawancara kepada para mahasiswa. Setelah mengidentifikasi masalah, kemudian kami melakukan kajian literatur untuk membangun solusi yang mungkin yaitu pengembangan aplikasi "Belajar Kriptografi" berbasis Android. Prototipe dikembangkan berdasarkan pendekatan RAD seperti berikut ini:
(1) Analisis Kebutuhan perangkat lunak dilakukan dengan wawancara semi terbuka terkait materi kriptografi seperti operasi XOR, konversi ASCII, Caesar Cipher, Vigenere Cipher, dan RSA.

(2) Perancangan dilakukan menggunakan UML berupa diagram use case dan aktifitas yang kemudian dituangkan menjadi prototipe low-fidelity merupakan bentuk awal perancangan sebuah aplikasi untuk dapat dijadikan sebagai bahan konstruksi. prototipe ini masih belum detil (Khatimah, 2018).

(3) Konstruksi dilakukan untuk memperbaiki prototipe yaitu menggunakan bahasa Java yang merupakan bahasa pemograman berorientasi objek (Retnoningsih et al., 2017). Prototipe disini sudah berupa aplikasi interaktif dan siap digunakan. Pada tahapan ini juga dilakukan pengujian menggunakan system usablity scale (SUS).

(4) Implementasi. Aplikasi "Belajar Kriptografi" di-publish pada Play Store.

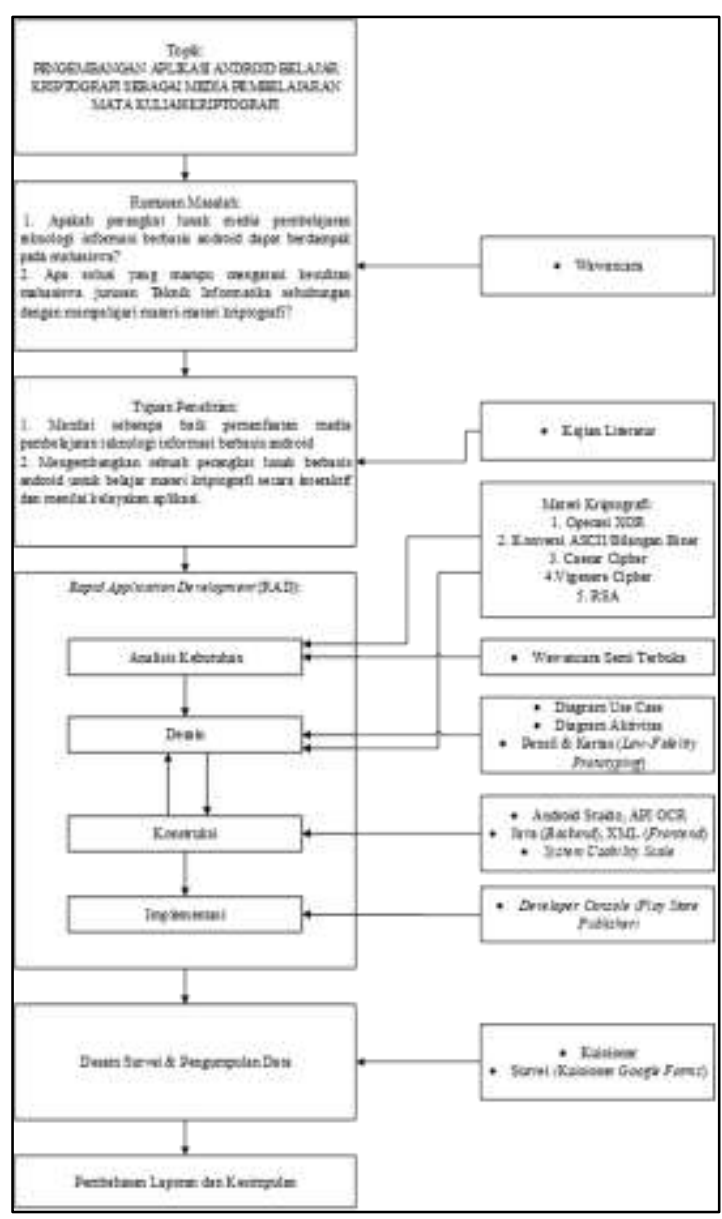

Gambar 1. Diagram Tahapan Penelitian 
Setelah prototipe dibuat, kemudian kami menggunakan survei berupa kuesioner. Kami membuat membuat daftar pertanyaan yang diajukan pada responden dalam berbentuk sampel dari sebuah populasi (Nofianti \& Qorimah, 2017). Survei yang dilakukan menggunakan pendekatan kuantitatif merupakan salah satu upaya pencarian ilmiah yang didasari oleh filsafat positivisme yang beroperasi dengan aturan-aturan yang ketat mengenai logika, kebenaran, hukum-hukum, dan prediksi (Dharma, 2008). Untuk memperkuat hasil penelitian, kami menggunakan data primer seperti yang telah dijelaskan oleh (Irwanto et al., 2019).

Penentuan jumlah sampel penelitian yang diambil adalah sebesar 43 subjek karena dihitung menggunakan rumusan Gay yang mengambil $20 \%$ sampel dari populasi yang tersedia (Andriani, 2015). Populasi penelitian adalah sebesar 215 orang. Sedangkan sampel untuk ahli materi adalah sebanyak 6 subjek.

Metode pengembangan perangkat lunak yang digunakan adalah Rapid Application Development (RAD) dimana merupakan sebuah metode pengembangan perangkat lunak yang berguna untuk mengembangkan sebuah perangkat lunak yang memiliki tingkat kedinamisan yang tinggi, ketersediaan waktu dan anggaran biaya pengembangan yang terbatas, untuk kebutuhan informasi terkini secara cepat, dan memerlukan interaksi hubungan dekat yang personal (Susilowati \& Negara, 2018).

Pengembangan perangkat lunak yang merupakan sebuah proses iteratif yang memungkinkan pengembang untuk mengembangkan perangkat lunak komputer yang berkualitas tinggi (Sari, 2018) dan dipilih untuk menggunakan metode RAD karena dapat mudah untuk diamati, lebih fleksibel, dan memiliki biaya yang minim (Aswati et al., 2017).

Aplikasi dievaluasi menggunakan SUS (System Usability Scale) yang merupakan kuisioner terstandarisasi untuk menilai kebergunaan dari sistem atau aplikasi. SUS telah digunakan oleh banyak penelitian yang terkait dengan penilaian kebergunaan sistem atau aplikasi (Lewis, 2018).

Selain SUS, kami juga melakukan pengujian penerimaan aplikasi kepada mahasiswa maupun ahli materi (dosen). Berikut ini adalah indikator-indikator penelitian yang dikembangkan:

Tabel 1. Indikator Penerimaan Mahasiswa

\begin{tabular}{ll}
\hline No & Indikator \\
\hline 1 & $\begin{array}{l}\text { Dengan adanya perangkat lunak "Belajar } \\
\text { Kriptografi" anda memiliki ketertarikan untuk }\end{array}$ \\
\hline
\end{tabular}

\begin{tabular}{ll}
\hline & mempelajari materi dalam mata kuliah \\
kriptografi. & Anda termotivasi untuk belajar mata kuliah \\
2 & $\begin{array}{l}\text { kriptografi saat memanfaatkan perangkat } \\
\text { lunak "Belajar Kriptografi". }\end{array}$ \\
& $\begin{array}{l}\text { Anda tertarik mempelajari pelajaran mata } \\
\text { kuliah kriptografi yang disampaikan dengan }\end{array}$ \\
& $\begin{array}{l}\text { menggunakan perangkat lunak "Belajar } \\
\text { Kriptografi". } \\
\text { Kegiatan belajar dengan menggunakan } \\
\text { perangkat lunak "Belajar Kriptografi" } \\
\text { membuat anda lebih memahami materi } \\
\text { kriptografi yang disampaikan. }\end{array}$ \\
\hline
\end{tabular}

Sumber: (Adam \& Syastra, 2015)

Tabel 2. Indikator Penerimaan Ahli Materi (Dosen)

\begin{tabular}{|c|c|}
\hline No & Indikator \\
\hline 1 & $\begin{array}{l}\text { Kesesuaian Isi dan Tujuan Aplikasi dengan } \\
\text { Beberapa Poin di RPS (Rencana } \\
\text { Pembelajaran Semester) Mata Kuliah } \\
\text { Kriptografi Universitas Esa Unggul. }\end{array}$ \\
\hline 2 & $\begin{array}{l}\text { Kesesuaian Cara Penyampaian Materi } \\
\text { (Penyelesaian Soal Kriptografi) di Aplikasi } \\
\text { dengan Beberapa Jurnal yang dirujuk. }\end{array}$ \\
\hline
\end{tabular}

Sumber: (Astra et al., 2012)

Penilaian terhadap SUS dan penerimaan mahasiswa/ahli materi menggunakan skala antara 1 sampai 5 (Skala Likert). Berikut ini merupakan tabel yang menjelaskan Skala Likert secara lebih rinci:

\section{Tabel 3: Skala Likert}

\begin{tabular}{lll}
\hline Skala Likert & Nilai & Keterangan \\
\hline STS & 1 & Sangat Tidak Setuju \\
TS & 2 & Tidak Setuju \\
N & 3 & Netral/Biasa Saja \\
S & 4 & Setuju \\
SS & 5 & Sangat Setuju
\end{tabular}

Sumber: (Mawardi, 2019)

Setelah seluruh data sudah diperoleh bedasarkan metode yang dipaparkan, maka data akan dianalisis. Berikut ini merupakan rumus untuk memperoleh persentase dari data yang telah diperoleh (Tohari et al., 2020)

Keterangan:

$$
P=\frac{f}{n} \times 100 \%
$$

- $P=$ Persentase skor;

- $f=$ Frekuensi yang muncul dari data

- $\mathrm{n}=$ Total data

Frekuensi yang muncul dari data (variabel $f$ ) didapatkan dari total dari nilai skala likert $(1 \mathrm{~s} / \mathrm{d}$ 5) dikalikan dengan jumlah kemunculanya. 
Adapun, total data (variabel $n$ ) didapatkan dari jumlah responden dikali dengan nilai maksimal skala likert yaitu sebesar 5 .

Adapun pada untuk perhitungan, skor System Usability Scale menggunakan rumusan berikut (Lewis, 2018), yaitu:

SUS $=2.5(20+($ SUS $1+$ SUS3 + SUS5 + SUS7 + SUS9) - (SUS2 + SUS4 + SUS6 + SUS8 + SUS10)).

\section{Hasil dan Pembahasan}

Pembahasan di dalam laporan dibagi ke dalam dua sub-bab utama yaitu pengembangan perangkat lunak dan hasil penelitian.

\section{Pengembangan Perangkat Lunak}

Tahapan yang dilakukan pertama kali adalah menyusun tabel kebutuhan fungsional, non-fungsional dan teknologi untuk mencari tahu kebutuhan primer yang diperlukan dalam mengkonstruksi perangkat lunak. Setelah itu, desain dilakukan dengan menyusun diagram UML dengan hasil sebagai berikut:

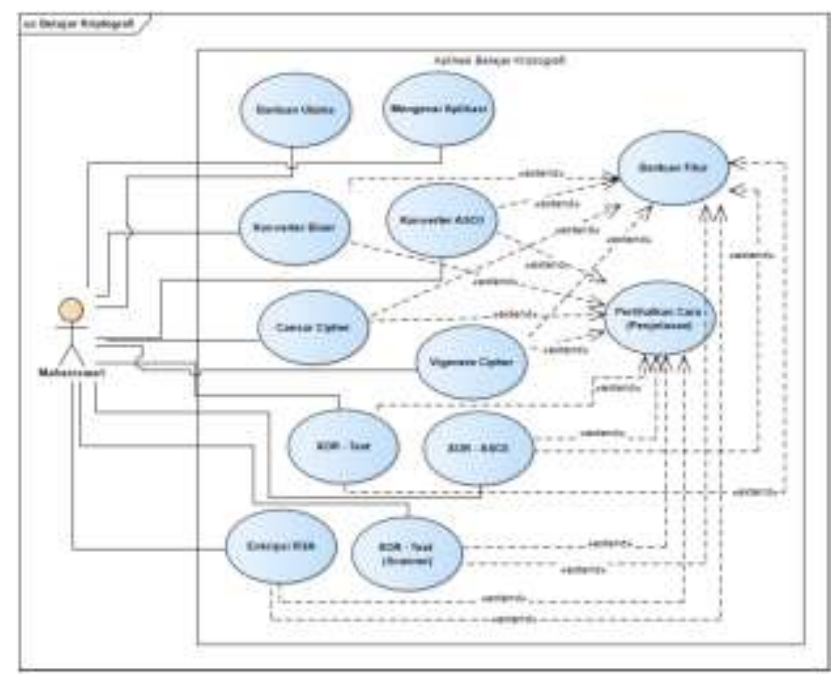

Gambar 2. Perancangan Diagram Use Case

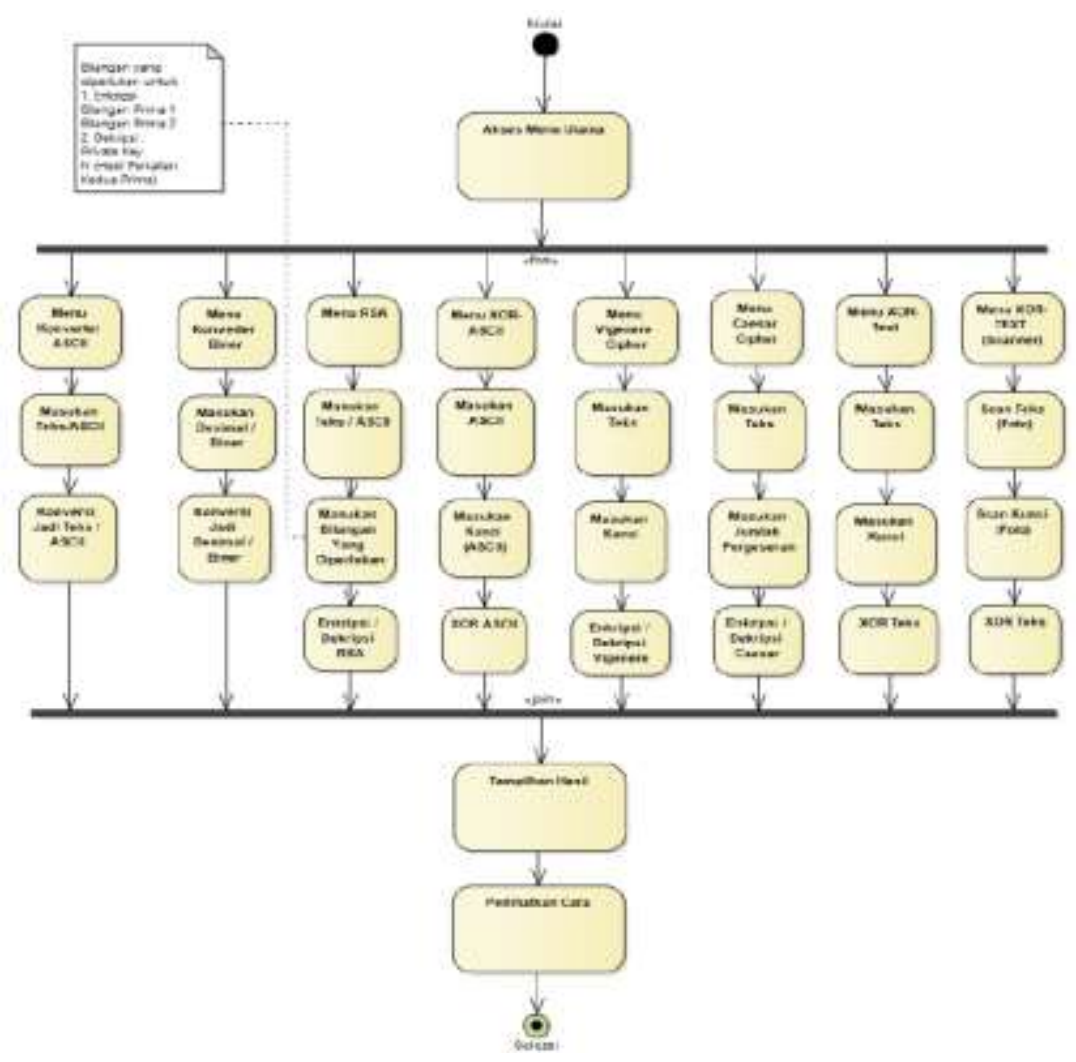

Gambar 3. Perancangan Diagram Aktivitas 


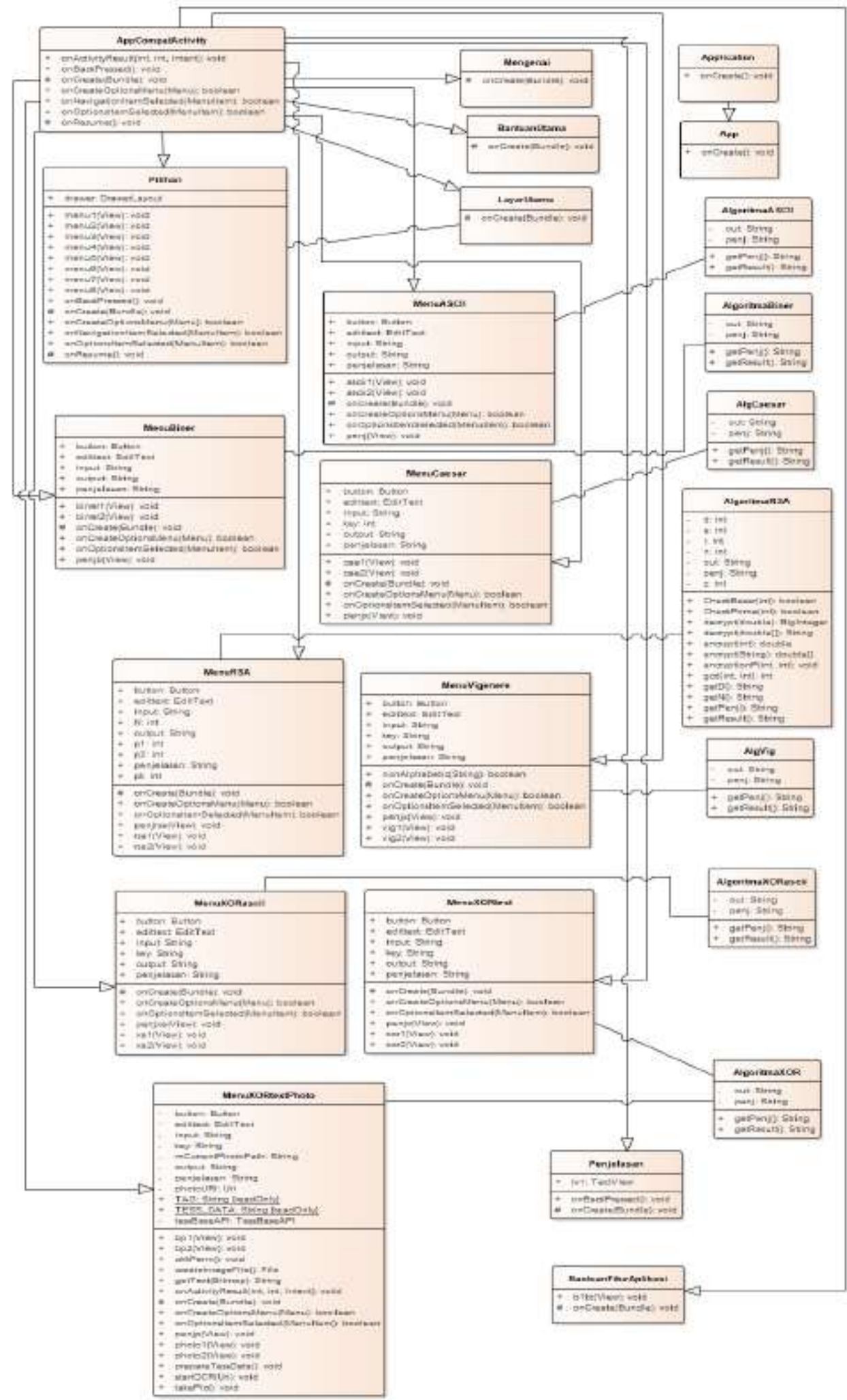

Gambar 4. Perancangan Diagram Kelas

Setelah diagram UML telah dirancang, maka dilakukan perancangan purwarupa lowfidelity dengan metode sketching pada lembar kertas. Hasli purwarupa kemudian akan dikonstruksi menggunakan perangkat lunak android studio yang merupakan IDE (Integrated
Development Environment) resmi untuk pengembangan aplikasi Android dan bersifat open source atau gratis (Juansyah, 2015).

Berikut ini merupakan tampilan perangkat lunak hasil konstruksi: 


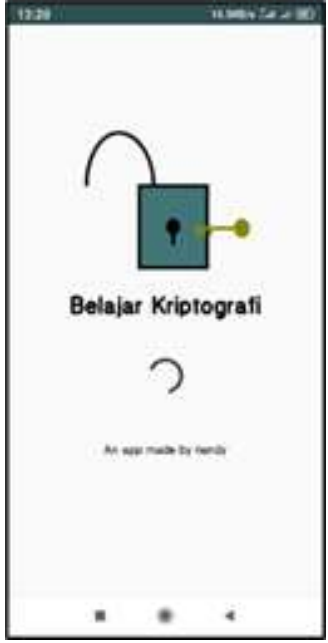

Gambar 5. Tampilan Splash Screen

Gambar di atas merupakan tampilan aktivitas pertama kali ketika pengguna mengakses aplikasi. Akan ditampilkan loading berupa progress dialog selama beberapa detik sebelum dialihkan ke halaman beranda.

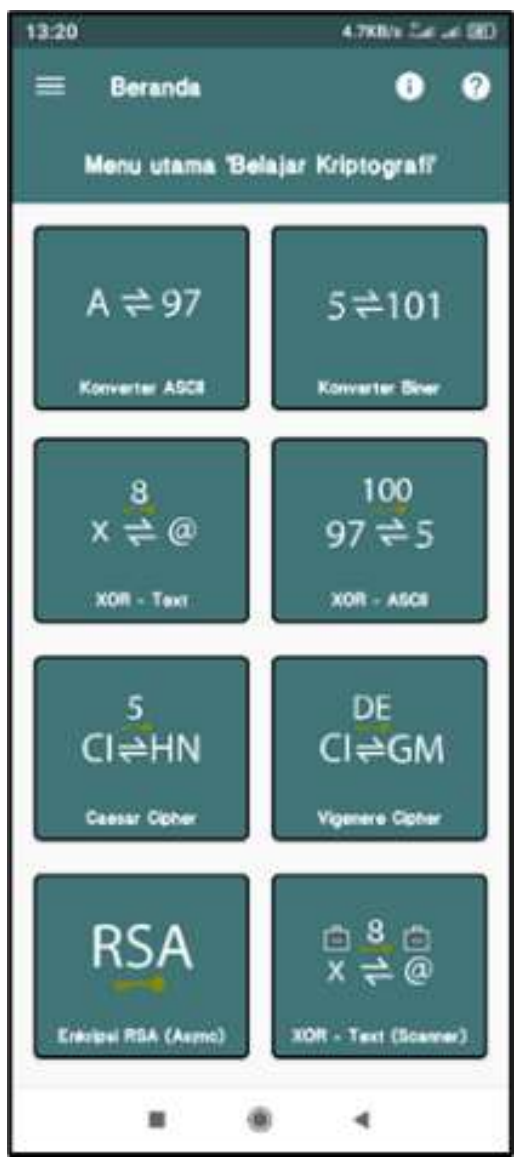

Gambar 6. Tampilan Beranda

Gambar 6 merupakan tampilan pilihan menu yang dapat digunakan oleh pengguna. Ketika salah satu menu diakses, maka akan dialihkan ke halaman tampilan fitur.

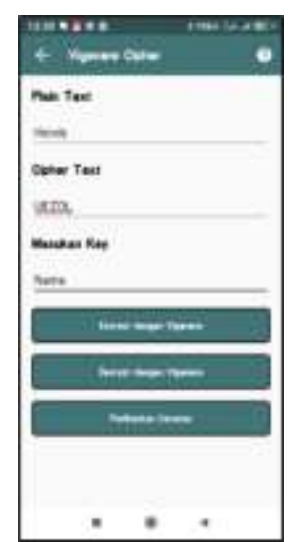

Gambar 7. Tampilan Fitur

Gambar di atas merupakan tampilan salah satu fitur yaitu Vigenere Cipher. Pengguna akan disediakan beberapa kolom untuk melakukan enkripsi serta dekripsi bedasarkan metode yang dipilih pada halaman beranda.

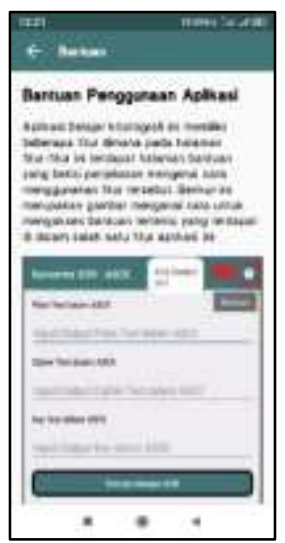

Gambar 8. Tampilan Bantuan

Gambar di atas merupakan tampilan bantuan penggunaan aplikasi secara garis besar pagi pengguna agar dapat mengakses bantuan fitur aplikasi. Tampilan bantuan fitur menyerupai tampilan bantuan pada gambar di atas.

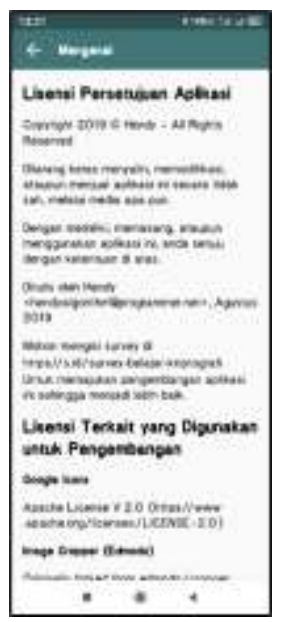

Gambar 9. Tampilan Mengenai 
Gambar 9 memuat tampilan informasi aplikasi dimana terdapat daftar lisensi pustaka yang digunakan dalam mengembangkan perangkat lunak dan lisensi persetujuan penggunaan perangkat lunak.

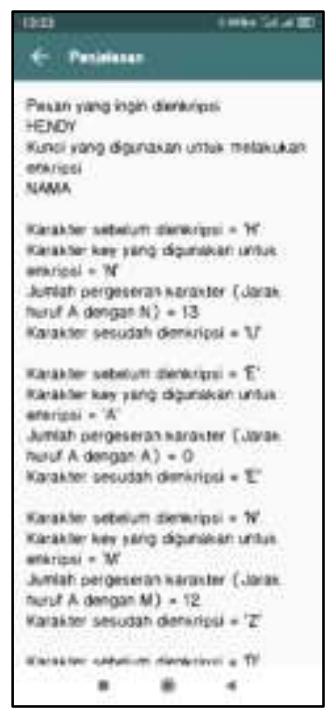

Gambar 10. Tampilan Penjelasan

Gambar 10 memuat penjelasan mengenai tahapan-tahapan penyelesaian soal kriptografi yang dimasukan sebagai masukan ke perangkat lunak.

Konstruksi perangkat lunak dikembangkan dan dilanjutkan menggunakan uji coba setiap fitur atau fungsi di dalam aplikasi. Pengujian ini menggunakan metode Black Box yang merupakan uji fungsional dari aplikasi agar dapat diimplementasikan dengan fungsi yang sesuai dengan harapan (Lestari \& Latifah, 2019). Apabila sudah sesuai dengan harapan, aplikasi akan diimplementasikan ke pasar perangkat lunak android. Berikut ini merupakan hasil implementasinya:

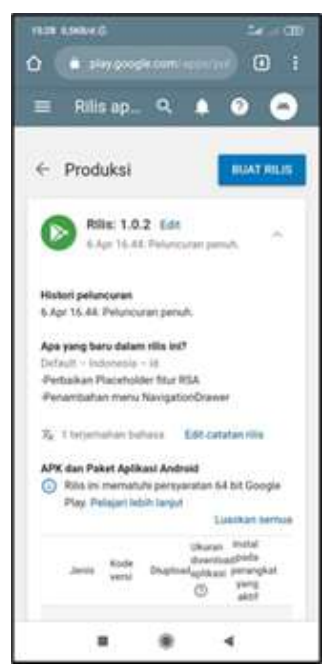

Gambar 11. Hasil Implementasi
Aplikasi "Belajar Kriptografi" memiliki tautan Play Store yang dapat diakses oleh publik, yaitu https://s.id/wAAPH.

\section{Hasil Penelitian}

Skor hasil perhitungan yang diperoleh pertama adalah SUS (System Usability Scale). Responden dari kuisioner SUS adalah sejumlah 43 subjek penelitian dari mahasiswa universitas esa unggul jurusan teknik informasika. Berikut ini merupakan akumulasi skor SUS yang diperoleh:

Tabel 4. Akumulasi Skor SUS dari 43 Responden

\begin{tabular}{ll}
\hline Pernyataan & Skor \\
\hline SUS 1 & 168 \\
SUS 2 & 98 \\
SUS 3 & 185 \\
SUS 4 & 91 \\
SUS 5 & 174 \\
SUS 6 & 100 \\
SUS 7 & 178 \\
SUS 8 & 73 \\
SUS 9 & 170 \\
SUS 10 & 113 \\
\hline
\end{tabular}

Berikut ini merupakan perhitungan dari. Total Skor SUS bedasarkan data yang terdapat pada tabel di atas, yaitu (1) Total Skor SUS = $2.5^{\star}(20+(875-475) / 43) ;(2)$ Total Skor SUS = $2.5^{\star}(20+9.3023)$; (3) Total Skor SUS = 2.5*29.3023; (4) Total Skor SUS = 73.255.

Setelah itu, didapatkan survei pengguna perangkat lunak yang dihitung menggunakan persentase skor likert setiap masing-masing pernyataan indikator. Selain itu, ditampilkan juga frekuensi pernyataan skala likert dari hasil survei yang diperoleh. Berikut ini merupakan tampilan datanya dalam bentuk tabel:

Tabel 5. Rangkuman Survei Pengguna

\begin{tabular}{lll}
\hline Pernyataan & Akumulasi & Persentase \\
\hline Pernyataan 1 & 176 & $81,86 \%$ \\
Pernyataan 2 & 164 & $76,28 \%$ \\
Pernyataan 3 & 169 & $78,60 \%$ \\
Pernyataan 4 & 165 & $76,74 \%$ \\
\hline
\end{tabular}

Bedasarkan rangkuman hasil survei tersebut dapat dideskripsikan rata-rata pengguna berpendapat bahwa aplikasi "Belajar Kriptografi" memberikan dampak terhadap ketertarikan para pengguna dalam mempelajari 
mata kuliah kriptografi. Hal ini disebabkan karena secara keseluruhan, persentase survei tersebut berada di dalam range setuju (60\%$80 \%)$ di skala likert.

Tabel 6. Frekuensi Pernyataan Skala Likert Pada Survei Pengguna

\begin{tabular}{lllll}
\hline Pernyataan & \multicolumn{4}{c}{ Frekuensi Pernyataan } \\
\cline { 2 - 5 } Skala Likert & $\mathbf{1}$ & $\mathbf{2}$ & $\mathbf{3}$ & $\mathbf{4}$ \\
\hline Sangat Tidak & 0 & 1 & 0 & 0 \\
Setuju & & & & \\
Tidak Setuju & 0 & 1 & 0 & 0 \\
Netral & 10 & 10 & 11 & 11 \\
Setuju & 19 & 24 & 24 & 28 \\
Sangat & 14 & 7 & 8 & 4 \\
Setuju & & & & \\
\hline
\end{tabular}

Lebih dari $70 \%$ responden mengeluarkan pernyataan setuju dan sangat setuju terhadap masing-masing pernyataan yang diajukan di dalam survei.

Pada akhirnya, diperoleh survei ahli materi untuk menilai kesesuaian antara penjelasan di dalam perangkat lunak sebagai media pembelajaran dengan standar ahli materi. Berikut ini merupakan rangkuman serta frekuensi bedasarkan masing-masing pernyataan:

Tabel 7. Rangkuman Survei Ahli Materi

\begin{tabular}{lll}
\hline Pernyataan & Akumulasi & Persentase \\
\hline Pernyataan 1 & 27 & $90 \%$ \\
Pernyataan 2 & 27 & $90 \%$ \\
\hline
\end{tabular}

Bedasarkan tabel di atas, dapat dideskripsikan bahwa para rata-rata ahli materi memberikan pernyataan pada area sangat setuju dengan besar perolehan persentase sebesar $90 \%$ pada kedua pernyataan.

Tabel 8. Frekuensi Pernyataan Skala Likert Pada Survei Ahli Materi

\begin{tabular}{|l|l|l|}
\hline \multirow{2}{*}{$\begin{array}{l}\text { Pernyataan Skala } \\
\text { Likert }\end{array}$} & $\begin{array}{l}\text { Frekuensi } \\
\text { Pernyataan }\end{array}$ \\
\cline { 2 - 3 } & $\mathbf{1}$ & $\mathbf{2}$ \\
\hline Sangat Tidak Setuju & 0 & 0 \\
\hline Tidak Setuju & 0 & 0 \\
\hline Netral & 1 & 0 \\
\hline Setuju & 1 & 3 \\
\hline Sangat Setuju & 4 & 3 \\
\hline
\end{tabular}

Dari hasil suvei pada tabel di atas dapat dideskripsikan bahwa sebanyak lebih dari $80 \%$ responden (ahli materi) memberikan pernyataan setuju dan sangat setuju terhadap kedua pernyataan. Tidak terdapat satupun dari keenam ahli materi yang memberikan pernyataan sangat tidak setuju ataupun tidak setuju. Hal ini mengartikan bahwa penjelasan materi kriptografi yang disajikan sesuai standar para ahli materi.

\section{Kesimpulan}

Nilai SUS rata-rata yang diperoleh adalah sebesar 73,255 dengan grade sebesar B- (Lewis, 2018). Sebagian besar pengguna dan ahli materi menyutujui bahwa aplikasi ini sesuai dengan pernyataan-pernyataan yang diajukan dengan tingkat persetujuan ahli materi diatas $80 \%$ dan pengguna diatas $70 \%$.

Penulis menarik kesimpulan bahwa aplikasi ini sukses diimplementasikan dan memberikan dampak baik kepada para mahasiswa. Penulis juga menyimpulkan bahwa aplikasi ini memiliki daya kebergunaan yang sesuai dengan standar karena rata-rata nilai SUS berada di antara 67,7 - 87.4. Selain itu, dapat disimpulkan bahwa aplikasi sesuai dengan standar yang ditetapkan oleh ahli materi karena memiliki persentase total skor likert sebesar $90 \%$ pada kedua pernyataan.

\section{Referensi}

Adam, S., \& Syastra, M. T. (2015). Pemanfaatan Media Pembelajaran Berbasis Teknologi Informasi Bagi Siswa Kelas X SMA Ananda Batam. CBIS Journal, 3(2), 78-90.

Akbari, A., Liyanthy, M., \& Darmawan, F. (2015). Pembangunan Media Pembelajaran Untuk Konsep Multimedia.

Andriani, D. P. (2015). Metode Sampling. Universitas Brawijaya. www.debrina.lecture.ub.ac.id

Astra, I. M., Umiatin, \& Ruharman, D. (2012). Aplikasi Mobile Learning Fisika dengan Menggunakan Adobe Flash sebagai Media Pembelajaran Pendukung. Jurnal Pendidikan Dan Kebudayaan, 18(2), 174180.

https://doi.org/10.24832/jpnk.v18i2.79

Aswati, S., Ramadhan, M. S., Firmansyah, A. U., \& Anwar, K. (2017). Studi Analisis Model Rapid Application Development Dalam Pengembangan Sistem Informasi. Jurnal Matrik Mei ISSN: 1858-4144, 16(2), 20-27.

Dharma, S. (2008). Pendekatan, Jenis, dan Metode Penelitian Pendidikan. Direktorat Tenaga Kependidikan.

Irawan, M. D. (2017). Implementasi Kriptografi 
Vigenere Cipher Dengan PHP. 1, 11-21.

Irwanto, Nabila, F., Dewi, I. S., Idris, I., \& Fajrilah. (2019). Penggunaan Metode Deskriptif Kuantitatif Dalam Motivasi Kerja Terhadap Kinerja Karyawan Melalui Uji Regresi Linear Berganda. Jurnal Teknovasi November E-ISSN: 2540-8389, 6(3), 54-62.

Juansyah, A. (2015). Pembangunan Aplikasi Child Tracker Berbasis Assisted - Global Positioning System ( A-GPS ) Dengan Platform Android. Jurnal IImiah Komputer Dan Informatika (KOMPUTA), 1(1), 1-8.

Khatimah, H. (2018). Analisis Desain Purwarupa Website Pemerintah Provinsi Bedasarkan Prinsip Desain Nielsen. Universitas Islam Indonesia.

Lestari, C. T., \& Latifah, F. (2019). Aplikasi Pencatatan Keuangan Pribadi Dengan Analisa SWOT Menggunakan Algoritma Sequential Search Berbasis Mobile. Journal of Information System, Applied, Management, Accounting and Research (E-ISSN: 2598-8719), 3(2), 11-18.

Lewis, J. R. (2018). The System Usability Scale: Past, Present, and Future The System Usability Scale: Past, Present, and Future. International Journal of Human-Computer Interaction, 1-14. https://doi.org/10.1080/10447318.2018.14 55307

Limbong, T. (2015). Pengujian Kriptografi Klasik Caesar Chipper Menggunakan Matlab. Seminar Nasional Inovasi Dan Teknologi Informasi September, 77-80.

Mawardi. (2019). Rambu-rambu Penyusunan Skala Sikap Model Likert untuk Mengukur
Sikap Siswa. Jurnal Pendidikan Dan Kebudayaan September, 9(3), 292-304.

Nofianti, L., \& Qorimah. (2017). Review Buku: Metode Penelitian Survey.

Retnoningsih, E., Shadiq, J., \& Oscar, D. (2017). Pembelajaran Pemrograman Berorientasi Objek ( Object Oriented Programming ) Berbasis Project Based Learning. Informatics Fot Educators And Professionals Desember E-ISSN: 25483412, 2(1), 95-104.

Sari, D. K. (2018). Pengembangan Aplikasi Android Mobile Dictionary And Emulator Perintah Dasar Command Line Interface Linux dan Windows. Universitas Negeri Yogyakarta.

Simargolang, M. Y. (2017). Implementasi Kriptografi RSA Dengan PHP. JURNAL TEKNOLOGI INFORMASI JULI 2017 P. ISSN 2580-7927, 1(1), 1-10.

Suryadi, A., Nasution, A., \& Febrianti, E. L. (2018). Pengenalan dan Pelatihan Bahasa Pemograman Android Pada Siswa SMK Negeri 1 Air Joman - Kisaran. Jurdimas (Jurnal Pengabdian Kepada Masyarakat) Royal E-ISSN 2622-3813 Juli, 1(2), 1-4.

Susilowati, S., \& Negara, M. T. (2018). Implementasi Model Rapid Application Development (RAD) Dalam Perancangan Aplikasi E-Marktetplace. Jurnal TECHNO Nusa Mandiri Maret, 15(1), 25-30.

Tohari, H., Iwan, R. B., Suhasto, N., \& Kumalasari, N. (2020). Purwarupa Sistem Informasi Kepenasihatan Akademik. Smart Comp Januari E-ISSN: 2549-0796, 9(1), 56-61. 